\title{
O ARQUIVO PRIVADO SÃO CAETANO: FRAGMENTOS DE MEMÓRIA ${ }^{1}$
}

THE SÃO CAETANO PRIVATE ARCHIVE: FRAGMENTS OF MEMORY
Enviado em 13 de março de 2015
Aceito em 18 de junho de 2015
Manuela Areias Costa ${ }^{2}$

Resumo: Propomos algumas reflexões sobre arquivos privados, considerandoos como "lugares de memórias" e valiosas fontes de pesquisa pela especificidade dos tipos documentais que os caracterizam. Os diversos fragmentos de memória que os compõem, quando reunidos, revelam-se como locus privilegiado para o trabalho historiográfico e científico, possibilitando inúmeras descobertas e propostas de investigação. Para tanto, tomaremos como foco de análise o "Arquivo Privado São Caetano". Apresentaremos a origem dos seus documentos, a condição em que foram encontrados, os processos de organização arquivística, as possibilidades de pesquisa, bem como as referências de trabalhos pautados em fontes localizadas neste arquivo.

Palavras-chave: Arquivo privado. Memória. Trajetória histórica.

\begin{abstract}
This article reflects on private archives as "places of memory" and sources for research that are valuable for the uniqueness of the materials they contain. The diverse fragments of memory that are part of these archives, when combined together, reveal themselves to be ideal for historiographic and scientific researchand can provide innumerable discoveries and research possibilities. In this light, this article focuses on the São Caetano Private Archive. The origins of the archive's documents will be discussed, as well as the condition in which the materials were found. Also covered will be the organization of the archive, research possibilities, and the academic works based on materials found in the archive.
\end{abstract}

Keywords: Private archive. Memory. Historical trajectory.

\footnotetext{
1 O presente texto surgiu como resultado do trabalho de organização arquivística do Arquivo Privado São Caetano entre 2008 e 2009. O contato direto com as fontes, durante o processo de organização do ASC, possibilitou a elaboração desse texto.

2 Graduada em História pela Universidade de Federal de Ouro Preto (UFOP). Mestre em história pela Universidade Federal Fluminense (UFF). Doutoranda em História pela Universidade Federal do Rio de Janeiro (UFRJ). E-mail: manuelaareiasc@gmail.com
} 


\section{INTRODUÇÃO}

De uma maneira geral, as pessoas guardam documentos na tentativa de preservarem suas memórias e, por essa mesma via, suas próprias identidades. São correspondências, registros fotográficos, objetos, comprovantes e recibos, diários, anotações, enfim, lembranças pessoais ou de um grupo que indicam suas relações pessoais ou profissionais, seus interesses. A documentação guardada no desenrolar de nossas vidas, quando tomados em conjunto, revelam trajetórias de vida, como também gostos, hábitos e valores, constituindo o nosso próprio arquivo pessoal. ${ }^{3} \mathrm{O}$ arquivo pessoal e/ou privado, ${ }^{4}$ mesmo sendo composto por fragmentos e lacunas, apresenta-se como uma valiosa fonte de pesquisa para o investigador por manifestar a memória individual de seus acumuladores. É constituído pelas trajetórias desses indivíduos e pelas relações estabelecidas por eles com a sociedade. Como apontou Heloísa Bellotto, abrange

[...] documentos produzidos e/ou recebidos por uma pessoa física (cidadão, profissional, membro de família ou elemento integrante de uma sociedade), enfim, documentos que, preservados para além da vida dessa pessoa, constituem seu testemunho, como conjunto orgânico, podendo então ser aberto à pesquisa pública $\left(2006\right.$, p. 265). ${ }^{5}$

Porém, o arquivo privado não é apenas fruto da simples acumulação de documentos por um titular e da sua relação social. As pessoas envolvidas na organização desse arquivo também podem alterar sua acumulação e organização. Desse modo, é preciso considerar as intervenções feitas por parte do arquivista, que confere valor histórico aos documentos sob sua guarda, classificando-os a partir da maneira que reconhece suas estruturas, funções e atividades da entidade produtora.

O boom de pesquisas nas áreas da história da vida privada e da história do cotidiano, e a análise de trajetórias individuais, têm aumentado o interesse sobre os arquivos pessoais. Segundo Angela de Castro Gomes, o interesse crescente pelos

\footnotetext{
${ }^{3}$ Cf. HEYMANN, Luciana. Velhos problemas, novos atores: desafios à preservação dos arquivos privados. Rio de Janeiro: CPDOC, 2005, p.3. Cf., também, ARTIĖRES, Philippe. Arquivar a própria vida.Estudos Históricos. Centro de pesquisa e documentação de história contemporânea do Brasil da Fundação Getúlio Vargas. Rio de Janeiro: 1998, p. 10-11. Nesse texto Artiéres analisa um costume por nós compartilhado: "o arquivamento da vida". 4 Define-se como "arquivo privado" aquele que é "de uma família ou de seus membros, relativos às suas
atividades públicas e privadas, inclusive à administração de seus bens. Também chamado arquivo
pessoal ou arquivo familiar". Cf.DICIONÁRIO BRASILEIRO DE TERMINOLOGIA ARQUIVÍSTICA. Rio de
Janeiro: Arquivo Nacional, 2005, p.29.
}

5 BELLOTTO, Heloísa Liberalli. Arquivos permanentes: tratamento documental. 4.ed. Rio de Janeiro: FGV, 2006, p. 265. 
arquivos privados por parte dos historiadores é algo recente e corresponde a uma mudança de rumo fundamental nas práticas historiográficas, "onde emergem novos objetos e fontes para a pesquisa, a qual, por sua vez, tem que renovar sua prática incorporando novas metodologias, o que não se faz sem uma profunda renovação teórica." ${ }^{6} \mathrm{Tal}$ mudança ocorreu a partir de um movimento revisionista iniciado na década de 1970, quando os estudos de História Social passaram a privilegiar o papel dos indivíduo sem detrimento do estabelecimento de estruturas que organizavam as relações sociais. A crise dos paradigmas marxistas e funcional-estruturalistas impulsionou uma profunda revisão do processo histórico, levando à ampliação dos objetos, das fontes e à valorização do indivíduo comum enquanto agente transformador. A chamada "história vista de baixo", inaugurada com os estudos do historiador britânico Edward Palmer Thompson, representou essa mudança de foco, seguida mais tarde pelos micro-historiadores italianos, que atraídos pelo estudo dos "novos" atores da história, abriram novos caminhos para que os arquivos pessoais ganhassem importância como fontes de pesquisa, possibilitando que seus registros ocupassem um novo espaço nos debates historiográficos. ${ }^{7}$ Assim, a partir das novas tendências introduzidas na historiografia, as últimas décadas assistiram a uma valorização desses arquivos, associados, por um lado, ao registro das experiências vivenciadas pelos indivíduos e, por outro, a uma modalidade de "escrita de si". ${ }^{8}$

Dando sequência aos estudos que privilegiam os arquivos privados como fonte e/ou objeto de estudo, objetivamos apresentar, nas próximas linhas, o "Arquivo Privado São Caetano", o histórico dos seus documentos, a condição em que foram encontrados e os processos de organização arquivística de seu acervo. Por último, discutiremos as diversas possibilidades de pesquisas que tal arquivo oferece.

\footnotetext{
6 GOMES, Angela de Castro. Nas malhas do feitiço: o historiador e os encantos dos arquivos privados. Estudos Históricos. Rio de Janeiro, v. 21, jan./jun. 1998. p.122. Cf, tambem: PROCHASSON, Christophe. Atenção: verdade! arquivos privados e renovação das práticas historiográficas. Estudos históricos: arquivos pessoais, Rio de Janeiro, Fundação Getúlio Vargas, v.11, n. 21, p. 105-119, 1998.

${ }^{7}$ Cf.SHARP, Jim. A História vista de baixo. In: BURKE, Peter. A escrita da história: novas perspectivas. São Paulo: EDUNESP, 1992, p.39-62; THOMPSON, Edward Palmer. Senhores e caçadores: a origem da Lei Negra. Rio de Janeiro: Paz e Terra, 1987; DAVIS, Natalie Zemon. O retorno de Martin Guerre. Tradução de Denise Bottman. Rio de Janeiro: Paz e Terra, 1987; GINZBURG, Carlo. O queijo e os vermes: o cotidiano e as idéias de um moleiro perseguido pela Inquisição. Tradução de Maria Betânia Amoroso. São Paulo: Companhia das Letras, 1987.

8 Cf. HEYMANN, Luciana Q.Estratégias de legitimação e institucionalização de patrimônios históricos e culturais: o lugar dos documentos. Reunião de antropologia do Mercosul. Buenos Aires, 2009.
} 


\section{APRESENTAÇÃO DO ARQUIVO PRIVADO SÃO CAETANO, PROCESSOS DE ORGANIZAÇÃO E HISTÓRIA DA FAMÍLIA FERREIRA E}

\section{RAMOS}

O denominado Arquivo Privado São Caetano (ASC) encontra-se atualmente no Instituto de Ciências Humanas e Sociais da Universidade Federal de Ouro Preto (ICHSUFOP), nas dependências do Arquivo Histórico da Câmara Municipal de Mariana (AHCMM). Trata-se de um conjunto de documentos de origem privada, cuja unidade de sentido pode ser rastreada em quem o produziu, ou seja, nas pessoas ou familiares que acumularam os documentos no exercício de suas atividades. Durante os processos de análise e organização, constatou-se que a massa documental desse arquivo é formada por fragmentos de vida de dois núcleos familiares que se aproximaram, se envolveram e se dispersaram: a família Ferreira e a família Ramos. Ambas residiram no distrito de Monsenhor Horta, antiga freguesia de São Caetano, na cidade de Mariana, Minas Gerais. Os registros abrangem o período entre as décadas de 1840 e 1940, sendo eles os mais variados: partituras musicais, cartas, fotografias, receitas culinárias e médicas, cartões postais, publicitários e de visita e registros contábeis.

Os documentos que ora compõem o ASC foram localizados em 1993, no interior do sobrado, situado na Praça Luiz Macedo, antiga Rua do Comércio, distrito Monsenhor Horta, e se apresentavam em condições caóticas de conservação. Alguns moradores do referido distrito, sensibilizados com o estado de abandono do "casarão" e com a degradação dos diversos documentos encontrados, entraram em contanto com o departamento de História da UFOP, que buscou transferi-los para as dependências do ICHS. Ao ser entregue ao Instituto de História, a documentação foi embalada em caixas de papelão e abrigada no porão da sala onde se encontra o AHCMM, permanecendo ali guardada por seis anos, sem receber nenhum tipo de intervenção e tratamento. Segue abaixo a fotografia do sobrado de onde foram recolhidos os documentos. 


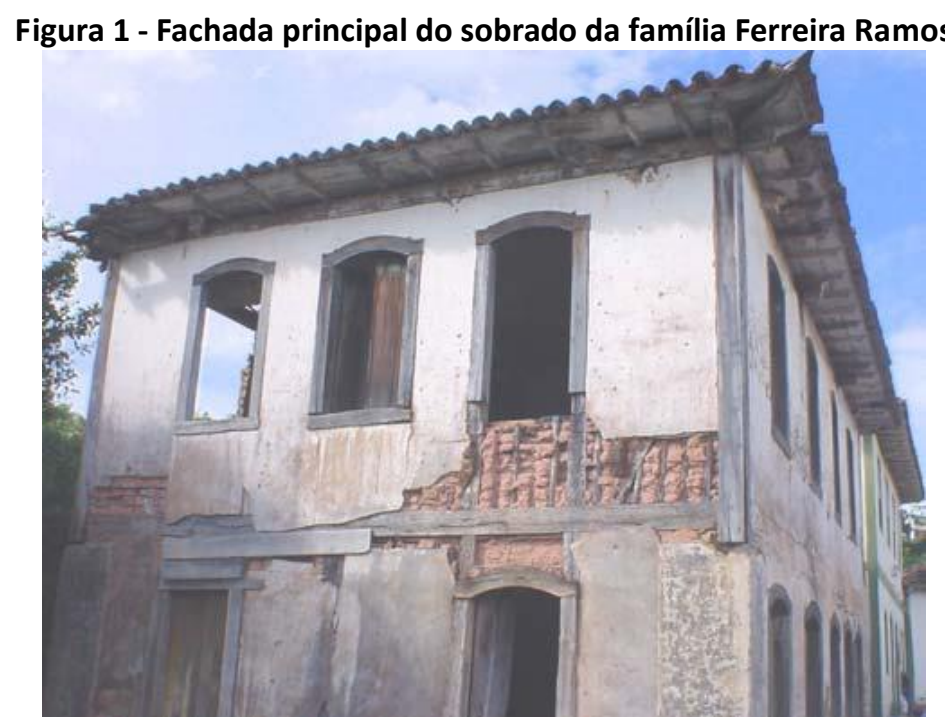

Fonte: LIMA, Kleverson. Práticas missivistas íntimas no início do século XX. (Mestrado em história, UFMG). Belo Horizonte: UFMG, 2007.LIMA, 2007, p. 14.

A partir de 1999, após o processo analítico de músicos e musicólogos, os documentos começaram a ser separados, higienizados, classificados e organizados provisoriamente. Segundo o Prof. José Arnaldo Coêlho de Aguiar Lima, responsável pelo acervo na época, gastou-se muito tempo no processo inicial de tratamento, em decorrência de ideias equivocadas sobre o caráter da documentação. Pensava-se que grande parte daqueles documentos era composta por partituras musicais e, por conta disso, somente os profissionais da área de música ou de musicologia seriam capazes trabalhar com tais registros. No entanto, após a consulta de alguns profissionais dessa área, contatou-se que a documentação poderia ser separada e identificada pelos próprios alunos do curso de História, pois a maior parte das partituras musicais trazia em seu cabeçalho o título, a autoria, o gênero musical e a parte instrumental a que pertencia. $^{9}$

Após os processos de higienização, separação de alguns documentos e reconhecimento do acervo na sua totalidade, criou-se fichas de identificação documental, construindo, desse modo, formulários e instruções de preenchimento para as seguintes categorias: manuscritos musicais, impressos musicais, iconografia, notas fiscais e periódicos. No processo de elaboração de formulários de identificação, foram consultados alguns profissionais na área de arquivologia e, especialmente, de musicologia, que auxiliaram na elaboração das fichas para os documentos musicais. Para as partes musicais foram produzidas fichas específicas de acordo com o RISM (Repertório Internacional de Fontes Musicais). ${ }^{10}$

9 LIMA, José Arnaldo C. A. Arquivo Histórico Monsenhor Horta: estilhaços. In: I Colóquio Brasileiro de Arquivologia e de Edição Musical. Mariana: FUNDARQ, 2003.

10 Idem. 
Em 2001, diversos problemas interferiram no processo de organização do arquivo, dentre eles a greve do funcionalismo público federal. Apesar do ASC, denominado, naquele momento, "Arquivo Histórico Monsenhor Horta", permanecer quase dois semestres letivos sem a colaboração dos alunos, neste mesmo ano, o musicólogo Paulo Castagna começou a atuar na organização dos manuscritos musicais sacros.

Segundo Kleverson Teodoro de Lima, no período entre 1999 e 2005 diferentes turmas trabalharam de maneira voluntária e esporádica na árdua higienização e acondicionamento provisório do acervo, proporcionando a limpeza, a identificação, a separação tipológica e o acondicionamento de seus documentos. Esse caráter de atuação ocorreu devido às limitações espaciais apropriadas para execução desses serviços, fato que limitava o número de participantes, e a ausência de financiamento para a realização do projeto, que dificultava a aquisição de materiais básicos, como máscaras e luvas, tornando, dessa forma, outras propostas de trabalhos em arquivos e temáticas de pesquisas mais sedutoras. ${ }^{11}$ Considerando esse conjunto de fatores, entre os anos de 1999 e 2008, os documentos passaram por um processo de higienização e identificação em fichas, porém, grande parte ficou excluída.

Somente em 2009, com o financiamento da FAPEMIG para o desenvolvimento do projeto intitulado Conservação e organização arquivísticas do Acervo Histórico de Monsenhor Horta (séculos XIX e XX), tornou-se possível a execução das atividades de forma contínua, resultando na organização total do acervo. O projeto proposto buscou promover a conservação e a organização do acervo segundo os parâmetros estabelecidos pelo Conselho Internacional de Arquivos (ISAD)..$^{12}$ A finalidade era produzir instrumentos de pesquisas que possibilitassem o acesso de pesquisadores ao conjunto documental e, assim, criar condições adequadas de pesquisa.

Muitos alunos bolsistas e voluntários atuaram neste novo projeto. Primeiramente, realizou-se a mudança da nomenclatura do acervo para "Arquivo Privado São Caetano", em virtude de a maior parte da documentação ter sido produzida ou recebida pelos seus titulares no período em que o distrito (atual Monsenhor Horta) era chamado de São Caetano, ${ }^{13} \mathrm{em}$ seguida, foi proposto um novo arranjo documental, estabelecendo dois fundos distintos. Em relação ao primeiro

11 LIMA, Kleverson Teodoro de.Práticas missivistas íntimas no início do século XX. Dissertação (Mestrado em História). Universidade Federal de Minas Gerais. Belo Horizonte: UFMG, 2007, p. 14.

12 CONSELHO INTERNACIONAL DE ARQUIVOS. ISAD(G): Norma geral internacional de descrição arquivística. 2.ed. Rio de Janeiro: Arquivo Nacional, 2001.

13 O distrito de Monsenhor Horta, chamado anteriormente de São Caetano, passou a ter sua denominação atual no ano de 1943. BARBOSA, Waldemar de Almeida. Dicionário histórico-geográfico de Minas Gerais. Belo Horizonte: Saterb, 1971, p.293. 
fundo, a documentação se refere às atividades da Família Ferreira e Ramos, já o segundo, faz referência às atividades da banda Sociedade Musical São Caetano. O trabalho visou não somente dar continuidade à higienização da documentação, como também a identificação em fichas padronizadas e o agrupamento dos documentos seguindo as normas tipológicas. Na medida do possível, buscou-se garantir a ordem original ou de procedência de todo o conjunto, mesmo sabendo que muitos foram misturados ao longo do tempo. ${ }^{14}$ Após esses procedimentos os documentos foram acondicionados em caixas adequadas e guardados em novas prateleiras, promovendo, também, um arranjo físico do arquivo. Na etapa conclusiva, elaborou-se um catálogo com informação sumária sobre cada peça documental e um banco de dados.

Durante as etapas de organização da massa documental foi possível identificar as seguintes espécies documentais: correspondências diversas, representação pictórica, fotografias, poemas, materiais escolares, textos teatrais, catálogos de instrumentos musicais, recibos comerciais, notas de recebimento de mercadorias, escritos jurídicos, receitas médicas e culinárias, cartões de visita, revistas, jornais e partituras musicais de variados gêneros (missas, credos, ladainhas, maxixes, dobrados, valsas, tangos, polcas, lundus, schottisches, modinhas). No entanto, a concentração documental mais expressiva refere-se às partituras musicais, correspondências diversas e escritos comerciais, como notas de recebimento de mercadorias, indicando, assim, a relação dos antigos proprietários desse acervo com a prática musical, epistolar e comercial.

O corpus documental do ASC versa sobre as atividades desempenhadas pelas famílias Ferreira e Ramos, moradores de São Caetano. As fontes indicam que o primeiro núcleo familiar teve como patriarca Antônio Martins Ferreira. A grande concentração de notas de recebimentos de mercadorias, cartas comerciais e livros de controle contábil, evidenciam que a sua principal ocupação era a de comerciante. Ferreira exerceu também o papel de juiz de paz, acumulando uma parte significativa de documentação jurídica. Seus filhos, Vicente Antero Ferreira e Antônio Eugênio Ferreira, deram prosseguimento às suas atividades comerciais, condição que pode se averiguada devido à continuidade das cartas comerciais. ${ }^{15}$

O segundo núcleo se refere à família Ramos. Felicíssimo Ramos, chefe da família, foi casado com Maria Cyrila e juntos tiveram treze filhos. Ramos possuía como

\footnotetext{
14 A documentação que compõe o ASC passou por diversas intervenções desde seu recebimento no ICHS, dentre as quais observamos que o princípio da proveniência não foi respeitado, pois, muitos documentos foram misturados e separados preliminarmente pela sua natureza, contrariando, forçosamente, toda a norma de organização arquivística, que reza pela manutenção da forma e da procedência.

${ }^{15}$ Cf. LIMA, Kleverson Teodoro de. São Caetano: vestígios do início de século XX. (Relatório geral sobre o projeto de pesquisa referente ao estudo das correspondências do acervo do histórico de Monsenhor Horta. ICHS/UFOP). Mariana, 2001.
} 
atividade principal a profissão de fogueteiro, vivenciando uma situação econômica mais fragilizada em relação à primeira família. No acervo encontram-se registros que comprovam este trabalho, como um livro sobre a arte de se fazer foguetes, cartas comerciais e pessoais. Existem, também, registros de sua aproximação com Antônio Ferreira por meio de relações comerciais. ${ }^{16}$

Nota-se a expressiva relação dos Ramos com a prática musical. O envolvimento musical da família iniciou-se com o seu patriarca (Felicíssimo Ramos), que atuou como mestre da banda São Caetano. Essa família foi responsável pela produção e acumulação de diversas partes musicais sacras e profanas, muitas relacionadas à Sociedade Musical São Caetano. A partir da análise dos documentos do acervo (atas de reuniões da sociedade musical, catálogos de instrumentos e partes musicais impressas e manuscritas) contatou-se que, além do patriarca, outros membros desta família se envolveram com a Sociedade Musical São Caetano e outras sociedades musicais da região, atuando como diretores, maestros, instrumentistas, compositores, copistas e representantes de instrumentos musicais. Arlindo Ramos, Caetano Ramos e José Alexandre Ramos, seguiram a carreira musical do pai (Felicíssimo Ramos), atuando como maestros da banda São Caetano e de outras bandas da região. Lindorifo, outro filho, junto com as mulheres da família, participou do coral musical da banda, que costumava se apresentar durante as celebrações religiosas. ${ }^{17}$

Outros indícios também explicam o acúmulo de documentos musicais relacionados à Sociedade Musical São Caetano pela família Ramos. Esta sociedade teve como sede, durante algum tempo, o casarão da família Ferreira Ramos, onde foram encontrados os documentos. Por essa razão existia no local uma grande quantidade de partituras de variados gêneros musicais. Além disso, até meados do século XX algumas sociedades musicais não tinham o costume de manter acervos documentais próprios nas suas sedes. Assim, muitos registros de suas práticas musicais ficavam guardados nas casas dos maestros e da diretoria da banda, ganhando um âmbito privado. ${ }^{18}$

\footnotetext{
16 Idem.

17 COSTA, Manuela Areias. Notas sociais: as práticas da banda da Sociedade Musical São Caetano (1890-1930), (monografia apresentada ao curso de história, UFOP). Mariana, 2010, p. 59.

18 Idem.
} 
Figura 2 - Partitura musical manuscrita. Dobrado, Lucrece. s/d, autor: Arlindo Ramos. Nota-se o carimbo da Sociedade Musical São Caetano no canto inferior direito.

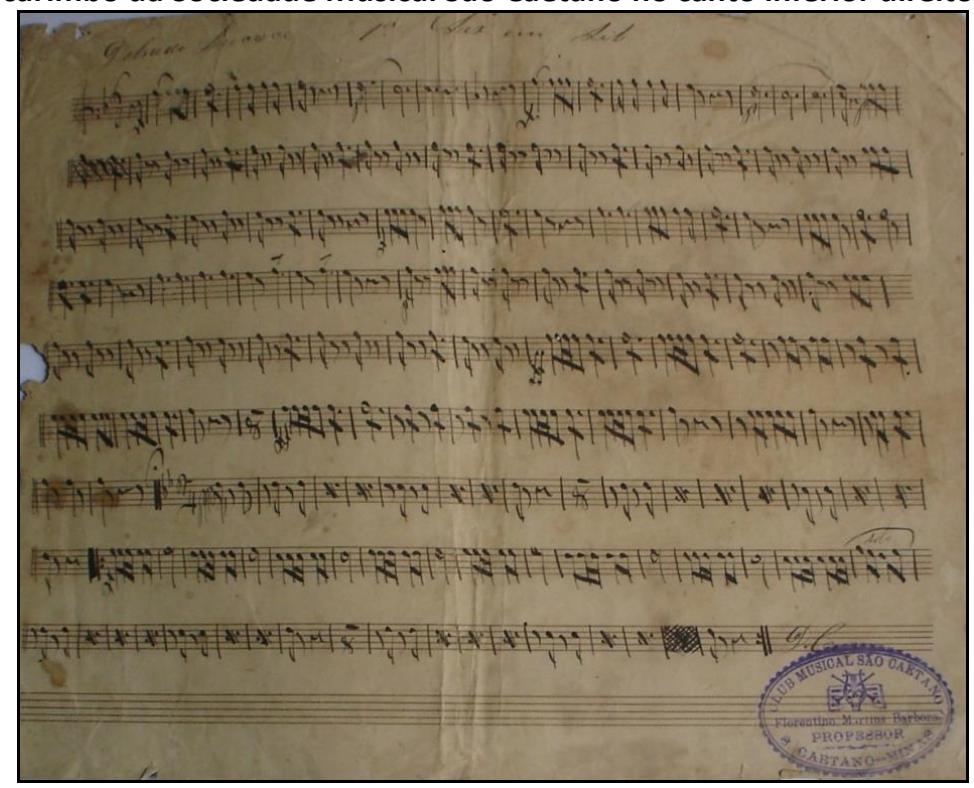

Fonte: Arquivo Privado São Caetano. Foto da autora.

Os dois núcleos familiares que acumularam essa documentação se aproximaram devido à relação conjugal de Vicente Antero Ferreira ${ }^{19}$ e Bilica Ramos na primeira metade do século XX. Este enlace explica a junção e a mistura dos documentos de famílias diferentes. Conforme o relato de um morador local, o casal morou em um sobrado do distrito até a década de 1950. Após este período, os cônjuges se mudaram para Sabará e grande parte dos documentos foi abandonada no "casarão" onde a família morava. ${ }^{20}$

\section{DESAFIOS E POSSIBILIDADES DE PESQUISAS}

"Entender os horizontes para um momento anterior ao ingresso de um arquivo privado em uma instituição de preservação de memória significa mergulhar no universo que o configurou, apreciando a relação que o "titular" mantém com seus documentos", ${ }^{21}$ pois só assim poderá conseguir analisar, avaliar e descrever toda a documentação que o retrata. A especificidade dos tipos documentais encontrados nos arquivos privados, bem como a complexidade de atividades e funções realizadas

\footnotetext{
19 Mais conhecido como Vicente Martins, nome herdado de seu pai, Antônio Martins Ferreira. Por isso a denominação do casarão como a "Casa da Família Martins".

20 RIBEIRO, Augusto (ex-maestro da banda Sociedade Musical São Caetano). Entrevista concedida à autora na sede da própria banda, Monsenhor Horta,19 de abril de 2009.

${ }^{21}$ VIANNA, Aurélio, et al. A vontade de guardar: lógica da acumulação em arquivos privados. Arquivo e administração, Rio de Janeiro, v.10-14, n.2, jul./dez. 1986, p. 63
} 
pelo(s) indivíduo(s) ao longo de sua(s) vida(s), revela ao arquivista um grande desafio no momento do seu tratamento técnico.

Esse desafio foi enfrentado e ainda vem sendo enfrentado pelas diversas equipes de alunos, professores e coordenadores, que atuaram e continuam atuando no processo de organização e conservação do acervo documental do ASC, nos últimos dezesseis anos. A mistura de documentos ao longo do tempo e a deterioração de algumas peças dificultam o entendimento do objetivo de seus titulares de os acumularem e, assim, a ordem e o significado dos documentos que foram guardados.

No entanto, os fragmentos da memória que o compõe, quando reunidos, abrem inúmeras possibilidades de pesquisas. Desse modo, o ASC revela-se como um locus privilegiado para o trabalho em diversas áreas do conhecimento. A memória dos seus titulares é decifrada e reinventada a cada análise e pesquisa proposta, evidenciando as relações sociais dos sujeitos a partir das suas mais diversas atividades (nas funções de comerciantes, músicos, leitores, compositores). ${ }^{22}$ Ao realizarmos um rápido levantamento bibliográfico de pesquisas que privilegiaram as fontes documentais desse acervo, encontramos trabalhos de pesquisadores envolvidos nas diversas etapas de sua organização e conservação.

Em 2001, Kleverson Teodoro de Lima, dedicado ao estudo das correspondências localizadas no ASC, finalizou o relatório São Caetano: vestígios do início de século $X X{ }^{23} \mathrm{O}$ trabalho desdobrou na sua monografia de bacharelado em história, intitulada São Caetano: cartas íntimas no início do século $X X$, defendida na Universidade Federal de Ouro Preto em $2003,{ }^{24}$ e na sua dissertação de mestrado Práticas missivistas íntimas do início do século $X X$, defendida quatro anos depois na Universidade Federal de Minas Gerais. ${ }^{25}$

$\mathrm{Na}$ área de linguística, destacamos o trabalho de monografia de bacharelado Estruturas negativas em cartas pessoais do século XIX e primeira metade do século XX, de Elaine Chaves. Neste trabalho, defendido no ano de 2003 no Departamento de Letras da Universidade Federal de Ouro Preto, Chaves objetivou estudar as construções

22 CORREIA, Fernanda Póvoa. O arquivo privado São Caetano: registro(s) de si, constituição de memórias e escrita da história. Dissertação (Mestrado em Historia). Universidade Federal de Ouro Preto, Mariana, 2014, p. 17.

23 LIMA, Kleverson Teodoro de. Op. Cit, 2001.

24 LIMA, Kleverson Teodoro de. São Caetano: cartas íntimas no início do século XX.Trabalho de conclusão de curso (Graduação em História). Universidade Federal de Ouro Preto, Mariana, 2003.

25 LIMA, Kleverson Teodoro de. Op. Cit, 2007. 
negativas em cartas pessoais do distrito de Monsenhor Horta entre o final do século XIX e a primeira metade do século XX. ${ }^{26}$

No mesmo ano, José Arnaldo Coêlho de Aguiar Lima, então professor de História da Arte da Universidade Federal de Ouro Preto e coordenador do projeto de organização documental do acervo (entre os anos de 1993 e 2006), publicou o texto Arquivo Histórico Monsenhor Horta: Estilhaços, nos anais dol Colóquio Brasileiro de Arquivologia e de Edição Musical, realizado na cidade de Mariana. Neste trabalho, Lima apresentou o Arquivo Histórico Monsenhor Horta, atualmente ASC, fornecendo informações preciosas sobre o achado da documentação, as condições em que o mesmo foi encontrado, a caracterização preliminar do acervo e as primeiras tentativas de organização. ${ }^{27}$

Cinco anos mais tarde, o musicólogo Paulo Castagna iniciou o projeto Patrimônio Arquivístico Musical Mineiro (PAMM), que abrangeu a higienização, organização, armazenamento, catalogação e digitalização (disponíveis em seis DVDs) de 350 manuscritos musicais sacros, entre estes se incluem credos, ladainhas e missas. 0 projeto, concluído no ano de 2009, resultou no Catálogo dos Manuscritos Musicais Sacros. $^{28}$ Contudo, deve-se mencionar que a separação estabelecida pela equipe coordenada por Castagna baseou-se na tipologia dos registros musicais, não considerando a ligação da documentação às coleções familiares de origem.

Incluo também o meu trabalho de monografia intitulado Notas Sociais: as práticas da banda da Sociedade Musical São Caetano (1890-1930), defendido no curso de história da Universidade Federal de Ouro Preto no ano de 2010, no qual explorei as práticas musicais da Sociedade Musical São Caetano, a partir da análise da documentação localizada no ASC(manuscritos e impressos musicais, catálogos, fotografias, revistas, entre outros). ${ }^{29}$

Recentemente, a dissertação O Arquivo Privado São Caetano: registro (s) de si, constituição de memórias e escrita da história, de Fernanda Póvoa Correia, defendida em 2014 no Programa de Pós-Graduação em História da Universidade Federal de Ouro Preto, na qual propõe algumas reflexões sobre arquivos privados enquanto campo de

\footnotetext{
${ }^{26}$ CHAVES, Elaine. Estruturas negativas em cartas pessoais do século XIX e primeira metade do século XX, Trabalho de conclusão de curso (Graduação em Letras). Universidade Federal de Ouro Preto, Mariana,2003.

27 LIMA, José Arnaldo C. A. Op. Cit, 2003.

28 O catalogo impresso e os DVDs encontram-se no Arquivo Privado São Caetano.

29 COSTA, Manuela Areias. Op. Cit. 2010.
} 
possibilidades para construção de biografias. Correia explorou, especialmente, os registros de Arlindo Agostinho Ramos. ${ }^{30}$

Finalizando, outras pesquisas vêm sendo desenvolvidas. Entre elas, destaco o trabalho de Lucas Lolli Vieira, atualmente mestrando pela Fundação Oswaldo Cruz. O artigo Entre Curas: as diferentes práticas medicinais em cidades mineiras no final do século XIX e início do século XX, publicado em 2012, aborda as práticas de cura em Minas Gerais, a partir da análise de diversos documentos localizados no ASC. ${ }^{31}$

Não obstante às valiosas pesquisas realizadas a partir da consulta de seus registros, o ASC foi pouco explorado. Esse fato justifica-se em virtude de sua condição precária, envolvendo a higienização e a organização de seus documentos, bem como a falta de instrumentos de busca até, pelo menos, o ano de 2010, o que impossibilitava a sua abertura ao público e, assim, o acesso à pesquisa. Porém, considerando a execução do projeto de conservação e organização, que resultou na elaboração de um novo arranjo, na organização total do acervo e na confecção de instrumentos de busca, espera-se que possa ser possível incrementar novas pesquisas pautadas em fontes encontradas em seu acervo.

\section{PALAVRAS FINAIS}

É indiscutível o valor histórico deste acervo, por guardar parte da memória social de Minas Gerais. Seus documentos podem revelar informações desconhecidas ou, até então, invisíveis da história e do mundo social. Evidenciam o cotidiano na freguesia de São Caetano do final do oitocentos e início do novecentos, bem como as experiências e práticas culturais de seus titulares, seus valores, suas perspectivas e seus hábitos.

Quase $70 \%$ da documentação que compõe o ASC é formada por manuscritos e impressos musicais, alguns, até então, desconhecidos. As partes musicais trazem vestígios daqueles que as fizeram - músicos e/ou copistas inseridos no universo musical -, informações sobre as ocasiões em que se apresentavam, o perfil do público que participou de suas apresentações, o tipo de instrumento utilizado e os gêneros musicais reunidos no seu repertório. Esses aspectos contribuem para a construção do quadro das atividades musicais em Minas Gerais. As correspondências acumuladas pelas duas famílias permitem mapear as redes de relações pessoais dos seus titulares,

${ }^{30}$ CORREIA, Fernanda Póvoa. Op. Cit, 2014.

${ }^{31}$ VIEIRA, L. Lucas. Entre Curas: as diferentes práticas medicinais em cidades mineiras no final do século XIX e início do século XX. PLURA, Revista de Estudos de Religião, vol. 13, 2012. 
oferecendo-nos chaves para compreender aspectos da vida social e política da região. Por meio delas é possível identificar o quadro econômico regional, pois são indícios importantes sobre o fluxo comercial até a década de $1940 .{ }^{32}$ Além dos registros musicais e das correspondências, outros documentos evidenciam ainda mais a importância deste acervo, que oferece um vasto campo de pesquisas para história social, musicologia, linguística e outras áreas do conhecimento.

\section{REFERÊNCIAS:}

ARTIÈRES, Philippe. Arquivar a própria vida. Estudos Históricos. Rio de Janeiro: Centro de pesquisa e documentação de história contemporânea do Brasil da Fundação Getúlio Vargas,1998.

BARBOSA, Waldemar de Almeida. Dicionário histórico-geográfico de Minas Gerais. Belo Horizonte: Saterb, 1971.

BELLOTTO, Heloísa Liberalli. Arquivos permanentes: tratamento documental. 4 ed. Rio de Janeiro: FGV, 2006.

CHAVES, Elaine. Estruturas negativas em cartas pessoais do século XIX e primeira metade do século XX.Trabalho de conclusão de curso (Graduação em Letras). Universidade Federal de Ouro Preto, Mariana,2003.

COSTA, Manuela Areias. Notas sociais: as práticas da banda da Sociedade Musical São Caetano (1890-1930). Trabalho de conclusão de curso (Graduação em História). Universidade Federal de Ouro Preto, Mariana, 2010.

CONSELHO INTERNACIONAL DE ARQUIVOS. ISAD (G): norma geral internacional de descrição arquivística. 2. ed. Rio de Janeiro: Arquivo Nacional, 2001.

CORREIA, Fernanda Póvoa. O Arquivo Privado São Caetano: registro (s) de si, constituição de memórias e escrita da história. Dissertação (Mestrado em História). Universidade Federal de Ouro Preto, Mariana, 2014.

DAVIS, Natalie Zemon. O retorno de Martin Guerre. Rio de Janeiro: Paz e Terra, 1987.

DICIONÁRIO Brasileiro de Terminologia Arquivística. Rio de Janeiro: Arquivo Nacional, 2005.

${ }^{32}$ Cf. LIMA, Kleverson Teodoro de. Op. Cit, 2007, p. 14. 
GINZBURG, Carlo. O queijo e os vermes: o cotidiano e as idéias de um moleiro perseguido pela Inquisição. São Paulo: Companhia das Letras, 1987.

GOMES, Angela de Castro. Nas malhas do feitiço: o historiador e os encantos dos arquivos privados. Estudos Históricos, Rio de Janeiro, v. 21, jan,/jun. 1998.

HEYMANN, Luciana Q. Velhos problemas, novos atores: desafios à preservação dos arquivos privados. Rio de Janeiro: CPDOC, 2005.

. Estratégias de legitimação e institucionalização de patrimônios históricos e culturais: o lugar dos documentos. Reunião de Antropologia do Mercosul. Buenos Aires, 2009.

LIMA, José Arnaldo C. A. Arquivo Histórico Monsenhor Horta: Estilhaços. In: I Colóquio Brasileiro de Arquivologia e de Edição Musical. Mariana: FUNDARQ, 2003.

LIMA, Kleverson Teodoro de. São Caetano: vestígios do início de século XX. (Relatório geral sobre o projeto de pesquisa referente ao estudo das correspondências do acervo do histórico de Monsenhor Horta. ICHS/UFOP). Mariana, 2001.

São Caetano: cartas íntimas no início do século XX. Trabalho de conclusão de curso (Graduação em História). Universidade Federal de Ouro Preto, Mariana, 2003.

. Práticas missivistas íntimas no início do século XX. Dissertação (Mestrado em História). Universidade Federal de Minas Gerais, Belo Horizonte, 2007.

NORRA, Pierre. Entre memória e história: a problemática dos lugares. In: Projeto História. São Paulo: PUC, n. 10, p. 07-28, dez. 1993.

PROCHASSON, Christophe. Atenção: verdade! arquivos privados e renovação das práticas historiográficas. Estudos históricos: arquivos pessoais. Rio de Janeiro, Fundação Getúlio Vargas, v.11, n. 21, p. 105-19, 1998.

SHARP, Jim. A história vista de baixo. In: BURKE, Peter. A escrita da História: novas perspectivas. São Paulo: EDUNESP, 1992.

THOMPSON, Edward Palmer. Senhores e caçadores: a origem da Lei Negra. Rio de Janeiro: Paz e Terra, 1987.

VIANNA, Aurélio, et al. A vontade de guardar: lógica da acumulação em arquivos privados.

Arquivo e Administração, Rio de Janeiro, v.10-14, n.2, jul./dez. 1986, p. 63.

VIEIRA, L. Lucas. Entre curas: as diferentes práticas medicinais em cidades mineiras no final do século XIX e início do século XX. PLURA, Revista de Estudos de Religião, vol. 13, 2012. 